\title{
Over Europese grenzen in het Nederlands bestuur $^{*}$
}

\author{
Mendeltje van Keulen
}

Het thema van het VNG-jaarcongres 2018 in Maastricht is 'Over grenzen'. Nederlandse politici en bestuurders moeten grenzen durven te verleggen. Niet zelden is dit een landsgrens, die in de regio heel wat dichter bij is dan in Den Haag. Meer dan de helft van de provincies grenst aan het buitenland en landsgrensoverschrijdende samenwerking is dus aan de orde van de dag. Nationale of EU-regels en subsidies kunnen helpen beleidsdoelstellingen te verwezenlijken die op regionaal of lokaal niveau belangrijk worden gevonden. Maar grensoverschrijdend beleid stuit in de praktijk ook op andere, 'Europese' grenzen. Zo ontdekt een ondernemer te laat dat Duitsland EU-richtlijnen anders interpreteert dan Nederland. Dan weer stelt nieuwe Brusselse wetgeving aanbestedingseisen, of hebben Europese besluiten een negatieve impact op grensregio's of op de visserij. Bij onbegrijpelijke, onuitvoerbare of botsende regels wordt er een spanning ervaren tussen Europees gemeenschappelijk beleid en Nederlandse decentralisatie. Dit essay focust op de grip op die Europese Unie (EU) als bestuurlijke uitdaging.

\section{Het wankele Europabewustzijn}

Welwillende onverschilligheid is veranderd in een sceptische houding, waarbij steun voor het proces van Europese eenwording afhankelijk is van de mate waarin het Nederlandse belang wordt gehonoreerd. Deze analyse van de Raad voor het Openbaar Bestuur over de Nederlandse omgang met Europa uit 2004 is vijftien jaar later nog onverminderd relevant. In de afgelopen jaren is het Euroscepticisme in Nederland gegroeid onder zowel laag-, middel- en hoogopgeleiden (Hakhverdian e.a., 2013). Nederlanders willen geen Nexit (SCP, 2016), hebben steun voor het lidmaatschap, maar zijn in het algemeen kritisch over het functioneren van de Europese Unie. Dit is de context waarin het Nederlandse Europabeleid zijn beslag krijgt.

Onder de over de EU geënquêteerde burgers zijn, zo mogen wij aannemen, ook de bestuurders en politici van de rijksoverheid en van de medeoverheden. Zij hebben daarbij een persoonlijke rol, omdat zij de voorkeuren van hun kiezers in goed

* Dr. M. (Mendeltje) van Keulen is lector Europese Studies aan de Haagse Hogeschool en oudgriffier van de commissie Europese zaken van de Tweede Kamer. Haar proefschrift 'Going Europe or going Dutch' uit 2006 behandelt Nederlandse overheidslobbies in Europa. Mendeltje van Keulen werkte eerder bij Instituut Clingendael en de WRR. Zij spreekt en schrijft regelmatig over de organisatie en praktijk van 'Grip op Europa' voor bedrijven, public affairs, studenten en bestuurder en is lid van het Comité van Aanbeveling van Hartman Young Professionals for Europe. Dit essay is een themabijdrage voor het VNG-jaarcongres 2018 in Maastricht 'Over grenzen'. 
beleid moeten vertalen en verantwoorden. Door de directe werking en doorwerking gaat die opdracht onvermijdelijk ook over (aspecten van) EU-beleid. Juist vanwege het proces van decentralisatie op terreinen die sterk door Brussels beleid worden bepaald, zoals regionaal beleid, is er een afbreukrisico voor de medeoverheden (provincies en gemeenten) en hun bestuurders die daarvoor ook politieke verantwoordelijkheid dragen (Mastenbroek e.a., 2013).

Het invoeren, uitvoeren en handhaven van deze Europese regels is wel beschreven als de minimale vorm van Europeanisering van een stad of regio. Een volgende stap is dat actief wordt geprobeerd Europese fondsen of regels te beïnvloeden. Via het Comité van de Regio's nemen vertegenwoordigers van medeoverheden deel aan de totstandkoming van EU-regelgeving. In Brussel zijn naast de permanente vertegenwoordiging van de regering (120 man) enkele tientallen regionale vertegenwoordigers actief, onder meer bij Huis van de Provincies en via de VNG-lobby in Brussel. Tezamen met de Brusselse activiteiten van de steden, zoals de G4, vormen deze vertegenwoordigers van alle Nederlandse bestuurslagen een eigen belangengroep, die interacteren met de Europese instellingen. Vaak trekken zij samen op; op deelterreinen (Europese fondsen) bestaan binnen de groep concurrerende doelstellingen. In Brussel vindt hoe dan ook enige vorm van socialisatie plaats; bijvoorbeeld door zich in netwerken te organiseren met andere regio's die de Europese instellingen relevante (regionale) informatie aanbieden door deelname aan conferenties en consultaties.

De indirecte route voor decentrale overheden loopt via de standpuntbepaling, waartoe samenwerking is vastgelegd in de Code interbestuurlijke verhoudingen. De koepels van gemeenten en provincies hebben een vaste plaats aan tafel bij het eerste afstemmingsoverleg over het 'nationale' standpunt over nieuwe EU-voorstellen. ${ }^{1}$ Commerciële lobbyisten die trachten een deelbelang in het Nederlandse standpunt vertaald te krijgen zijn hier wel eens jaloers op, zeker als zij horen dat de stoelen van IPO en VNG in dat wekelijkse overleg nog wel eens leeg blijven. Het lemma 'implicaties voor decentrale overheden' (extra taken, extra kosten) wordt dan ingevuld door een penvoerder van de centrale overheid. Eerder werd de mogelijkheid om niet alleen direct in Brussel, maar ook via de band van de rijksoverheid en de Tweede Kamer (Raadsfase) Europees beleid bij te sturen voor provincies nog een blinde vlek genoemd (Mastenbroek e.a., 2013). De casus over het lot van het cohesiebeleid verderop in dit essay lijkt hiervan een illustratie.

De opdracht van deze Europese public affairs is goed ingebed regionaal beleid te vertalen in Europese beleidskansen en weer terug naar de werkvloer. In de praktijk ligt hier een uitdaging voor deze vooruitgeschoven posten (Figee e.a., 2017). Medewerkers in Brussel of op internationale afdelingen op stadhuis of provinciehuis moeten vaak de nodige moeite doen om collega's van het nut en de kansen van Europa te overtuigen. Een groot internationaal survey-onderzoek onder het

1 Het zogeheten overleg over de beoordeling van nieuwe commissievoorstellen (werkgroep BNC) dat over elk voorstel een kabinetsappreciatie schrijft die de basis vormt voor het Nederlandse standpunt in de onderhandelingen. 
Eurocities netwerk toont aan dat er een grote mate van variatie is in de mate van Europeanisering van de aangesloten steden. Het Europabewustzijn is er op zijn best middelmatig (Verhelst, 2017). Specifiek bij de Nederlandse medeoverheden was al eerder een 'zwak beleidsmatig Europabewustzijn' gesignaleerd, waarbij beleidsmakers van decentrale overheden en departementen 'op het laatste moment even aan de jurist vragen of hun beleidskeuze nog Europeesrechtelijke problemen geeft' (Hessel, 2015). Gezien de enorme omvang van het Europese acquis op terreinen als milieu, aanbestedingen en sociaal beleid zal men bij een dergelijke toets ongetwijfeld op problemen stuiten. Met zo'n late constatering wordt het oordeel bevestigd dat Europa vooral een belemmering vormt, daarmee stijgt de frustratie, en daarmee het onbegrip.

Dit 'wankele' Europabewustzijn (Mastenbroek e.a., 2013) kan deels worden verklaard door het gebrek aan kennis van het Europese beleid en bestuur. Waar de Tweede Kamer en de regering bekende actoren zijn, zijn de (relevante) rollen van de Europese Commissie en Raad van Ministers bij veel ambtenaren en politici onbekend. Dat Europa structureel vaker aan de orde zou moeten komen in het onderwijs, is recent opnieuw in onderzoek bevestigd. Omdat het thema Europa nog niet altijd stevig in de eindtermen verankerd is, kost het docenten in het primair onderwijs (PO) en het voortgezet onderwijs (VO) - die zelf geen Europese opleiding hebben, veel tijd om materiaal bijeen te zoeken (Podium, 2018). Zonder die basiskennis is de EU-informatie die men ontvangt niet goed op waarde te schatten. Zo lijkt het Haagse systeem van Kamerbrieven voor en na Europese ministerraden die in het openbaar worden behandeld, op het eerste gezicht buitengewoon transparant. Maar als een van de 28 aan de onderhandelingstafel hebben ministers er alle belang bij in openbare stukken geen valkuilen te schetsen. Om die valkuilen te kunnen identificeren, en bijvoorbeeld vanuit de regio de realiteitszin van een standpunt in het Europese krachtenveld te kunnen toetsen, is eigen inzicht vereist.

Zelfs als kritische parlementariërs een subtiele politieke interpretatie in een implementatiewet voor EU-richtlijnen in de smiezen zouden hebben, zijn er belemmerende factoren tegen zichtbare grip op Brussel. De Wetenschappelijke Raad voor het Regeringsbeleid sprak in dit verband over perverse prikkels, of een vicieuze cirkel tussen zichtbaarheid, relevantie en betrokkenheid (WRR, 2007). Europa als bestuurslaag is weinig zichtbaar en daarmee niet relevant, en bestuurders voelen zich niet betrokken. Zonder nieuwsframe, in de vorm van prikkelende stellingen of conflicterende opinies, is er weinig media-aandacht, en daarmee wordt het beeld van geringe relevantie bevestigd. Er is daarbij ook weinig inzicht in de verantwoording van beleid en politici worden zo ook nauwelijks afgerekend op Brusselse activiteiten.

Deze analyse valt goed te illustreren met een recente casus: de voorbereiding van de besluitvorming in Nederland over de toekomst van de Europese fondsen, in 
jargon het 'cohesiebeleid'. ${ }^{2}$ Waar Den Haag inzet op minder betalen aan Brussel, zet de regio graag zijn kaarten op Europese plattelands- of innovatiebudgetten. De onderhandelingen over het toekomstige EU-budget voor de periode na 2020 zijn momenteel in volle gang; niet achter, maar voor de Brusselse schermen. In april vond de laatste ministerraad tussen de 28 landen plaats over het cohesiebeleid, voordat de Commissie de voorstellen voor de langetermijnbegroting zal doen. De laatste kans dus om vanuit het Nederlandse parlement en regering inbreng te leveren voor de plannen voor de toekomst van de fondsen. De vraag of timing voor een lobby van wezensbelang is (je kunt maar een keer op tijd zijn, anders ben je of te vroeg, of te laat, dixit Cruijff), lijkt hier een juist moment voor een goed inhoudelijk debat over dit dossier.

Maar het Tweede Kamerdebat dat was ingepland over deze Raad werd half april bij gebrek aan belangstelling schriftelijk afgedaan. Een schriftelijk overleg (SO); dat is Kamerjargon voor het vervangen van een gepland openbaar debat tussen politici door een correspondentie tussen ambtenaren en fractiemedewerkers. Dat besluit werd genomen in de Kamercommissie voor Europese Zaken, die de Raad waar minister Blok het cohesiestandpunt inbrengt, controleert. Kennelijk hadden de woordvoerders geen behoefte aan een zichtbaar openbaar debat over de Nederlandse inzet op de Europese fondsen. Dit besluit is vervolgens niet betwist door woordvoerders van Binnenlandse of Economische zaken, waar de lijnen met de decentrale insteek of belangen wellicht korter zijn. Op het moment dat de besluitvorming en de persberichten zullen uitgaan, zullen betrokkenen in Den Haag en Brussel terecht zeggen dat de onderhandelingen en daarmee de kans voor inbreng nu voorbij zijn.

Hoe kan het nu dat zo'n debat, over zo'n voor alle bestuurslagen relevant Europees onderwerp, geen aandacht krijgt? In de nationale politiek maken krantenkoppen en verontruste (burger-)lobby's dat de Kamer ergens bovenop zit. Maar ook voor pers en lobbyisten is Brussel een specialisme. Europa past in de beleidsvormende fase niet eenvoudig in een nieuwsframe. Redacties worstelen hoe Europa te verslaan. Het debat over de razendsnelle promotie van Junckers hulp Selmayr kwam gelegen. Kamerbrede verontwaardiging over een Eurofiele topambtenaar past in veel nieuwsframes. Maar de gelekte voorstellen voor het landbouwbeleid - voor Nederland als Agro-exporteur cruciaal - krijgen geen pennen in beweging. Zoals de Raad van State in het Jaarverslag 2017 stelt: 'een deel van de problematiek ligt in het feit dat media-aandacht in alle lidstaten vrijwel uitsluitend is gericht op nationale politiek'.

Dit essay ging tot nog toe in op het wankele Europabewustzijn in de beleidsvormende fase. Europees recht is bindend en autonoom na besluitvorming, en het is dan ook belangrijk dat dat proces van onderhandelingen goed wordt gevolgd. Maar ook in dat proces gaat het vaak om standpunt, inbreng en inzet. Er is over de volle breedte een schrijnend gebrek aan inzicht in het resultaat, de uitkomst en

2 Zie: www.rijksoverheid.nl/regering/bewindspersonen/mona-keijzer/documenten/kamerstukken/ 2018/04/09/antwoorden-op-kamervragen-over-raz-cohesie. 
de verantwoording van de onderhandelingen. Op het moment dat voor decentrale overheden kosten of aanpassingsdruk aan het licht komen, is het Brusselse niet meer van nationale keuzes te onderscheiden. Dit pleit des te meer voor een scherpe blik op het volledige proces van vorming, omzetting en implementatie van Europees beleid. Heeft de regering moeten aanpassen, is er sprake van een compromis, moest er water bij de wijn worden gedaan op cruciale artikelen? Pas bij grote crises (Securitel, grens voor woningbouwcorporaties, fijnstofnormen) gaat de aandacht uit naar wat Nederland eigenlijk in Brussel heeft bereikt. Politici praten liever over nieuwe plannen dan over verantwoording van de winst- of verliesrekening. Zo krijgt Brussel zonder tegenspraak makkelijk de schuld van ongewenst beleid, waar namens Nederland wel degelijk iemand heeft getekend.

\section{De Europese grens geslecht}

Alle bestuursniveaus, maar ook bedrijven, lobbyisten, ngo's worstelen met de inbedding van het Europese werk in 'normale' dagelijkse processen. Vaak valt Europa in een specialistische groef, waardoor de aansluiting niet tijdig wordt gezien. Uiteindelijk zou een ideale situatie er een zijn van mainstreaming in de vorm van 'gewone' dagelijkse betrokkenheid, afstemming of uitwisseling van Europese dossiers door vakcommissies of politici of bestuurders zonder (bij uitstek) een Europaportefeuille. Er is de afgelopen jaren veel aandacht geweest voor de mate van Europeanisering in centrale overheden en (regionale) parlementen. Zo was er onlangs een onderzoek naar het Schotse en Beierse parlement op basis van een meting van de (toegenomen) Europese dimensie in schriftelijke vragen (Hogenauer, 2017). In het kader van het spoor stutten van het wankele Europabewustzijn zijn er ook in Nederland hoopvolle initiatieven van onderop. De stad Amsterdam richtte een netwerk op van jonge EU-ambassadeurs die Brussel en de hoofdstad gaan verbinden. Dit jaar viert het HYPE-netwerk van de Stichting Fonds Hartman voor jonge mensen met een hart voor Europa, zijn tweede lustrum. ${ }^{3}$ Deze initiatieven kunnen leiden tot een groter Europa-bewustzijn, en daarmee een strategischer inbedding van initiatieven richting Europa met het oogmerk het EU-beleid te versterken.

De eerdergenoemde Hessel (2015) ziet het overbruggen van de scheiding tussen beleid en wetgeving als een ander aangrijpingspunt voor Europeanisering. Bij beleid gaat het om doelstellingen en instrumenten, bij recht om procedures en bevoegdheden, verboden en verplichtingen. Europees recht is ook gestoeld op doelstellingen (economie), en zeker de laatste jaren gaat het over hard beleid: klimaatneutraliteit bij bouwprojecten; of kansen voor het MKB. Europa kan dan gebruikt worden als netwerk voor kennisuitwisseling en bestuurlijke positione-

3 HYPE (https://hypenetwerk.wordpress.com/over-hype/missie/) is een netwerk dat medewerkers van (met name) decentrale overheden die met Europese zaken bezig zijn, door middel van opleiding met elkaar in contact brengt. Elke twee jaar zijn ongeveer 25 mensen HYPE-lid; zij vormen een kennisnetwerk door training en opleiding. De Stichting Fonds Hartman voor lokaal bestuur maakt HYPE mogelijk. 
ring of voor het pleiten voor innovatiegelden in een context die met dezelfde doelen bezig is. Het juridische Europese jargon laten aansluiten bij de taal van het beleid geeft kansen voor een Europese missie, visie en prioriteiten in jaarplannen, coalitieakkoorden en debatten. Immers, om op Europees niveau beleidswensen te realiseren is het belangrijk om strategisch te werk te gaan op een select aantal prioritaire dossiers.

Waar de regering en de Eerste en Tweede Kamer al jaarlijks een lijst bespreken van hun Europese prioriteiten, brengen ook de VNG en IPO deze in het interbestuurlijke overleg. Het zou interessant zijn om hierover een openbaar debat te organiseren tussen parlement, regering en decentrale overheden. Op welke dossiers lopen de Europese belangen van de Nederlandse bestuurslagen gelijk, waar botsen deze, en welke politieke keuze kan hieronder worden verantwoord? Als de Commissie bij monde van Frans Timmermans pleit voor betere regelgeving, wat betekent dat dan concreet voor gemeenten; welke Europese regels kunnen beter? (De Lange e.a., 2015). 'Debat en verantwoording van het Europees beleid (...) kunnen bijdragen aan versterking van democratische betrokkenheid', zoals de Raad van State in 2017 concludeert. Die prikkel, dus van het openbaar verantwoorden van Europese ambities en gemaakte keuzen, zal niet alleen moeten doorwerken in de regio, maar ook door lokale politici en bestuurders moeten worden ingezet.

De hierboven beschreven vicieuze cirkel (weinig politieke activiteit, weinig reuring door stakeholders en media-aandacht, weinig prikkels voor politieke profilering) kan worden doorbroken als de Europese activiteiten van rijksoverheid, stad, provincie en gemeente actief worden belicht. Dat betekent dat Europese initiatieven uit de technische groef moeten worden gehaald, en dat politieke keuzes hierin worden uitgelicht. In de Tweede Kamerverkiezingen van 2017 was Europa geen thema; ondanks de kans die hiertoe werd geboden door de enkele weken eerder in een Europees Witboek gepresenteerde Europese toekomstscenario's. Juist het komende jaar biedt kansen voor de communicatieve dimensie van het Europadebat en het verbinden van bestuursniveaus. De Europese verkiezingen van mei 2019 bieden de 26 Nederlandse Europarlementariërs en hun partijen de mogelijkheid om te verantwoorden welke aangepaste EU-richtlijnen, subsidiestromen of beleidswijzigingen in de afgelopen vijf jaar hun verdienste waren, waartegen zij hebben gestreden en op welke beleidsterreinen (fondsen, aanbestedingsregels, duurzame economie) zij meerwaarde zien in grensoverschrijdende samenwerking. Laten zij daarop door gans het land kritisch worden bevraagd.

\section{Literatuur}

Figee, E.L., J.F. Gosselt, P. Linders \& M.D.T. de Jong, 'The home front. Internal organization of public affairs in Dutch subnational governments', Journal of Public affairs, 2017/3, p. 1-8.

Hakhverdian, A., E. van Elsas, W. van der Brug \& T. Kuhn, 'Euroscepticism and education. A longitudinal study of 12 EU member states, 1973-2010', European Union Politics, 2013/4, p. 522-541. 
Hessel, B., 'Het Europees toezicht op staatssteun en de beleidskansen voor decentrale overheden en de rijksoverheid. Een beschrijving van de staatssteunregels vanuit het beleidsmatig Europabewustzijn', B. Hessel \& M. van der Velden (eds.), De Europese staatssteunregels 2015, Ars Aequi Wetseditie 2015, Nijmegen: 2015, p. 1-25.

Hogenauer, A., 'Regional parliaments questioning EU affairs', Journal of Legislative Studies, 2017/2, p. 183-199 (special issue: 'Regional parliaments. Effective actors in EU policy making?').

Keulen, M. van, Going Europe or going Dutch? How the Dutch government shapes European Union policy, proefschrift Universiteit Twente, Amsterdam: 2006.

Lange, E.E. de, R.A. Wessel \& N.S. Groenendijk, Europa als kans. 'Better Regulation' voor Nederlandse medeoverheden, Universiteit Twente, Enschede: 2015.

Mastenbroek, E., P. Zwaan \& D. Lieffering (m.m.v. M. Herweijer \& S. van Voorst), Provinciaal positiespel in Brussel en Den Haag. Een onderzoek naar de positie van provincies in Europese beleidsvorming, Radboud Universiteit, Nijmegen: 2013.

Podium bureau voor Educatieve Communicatie, Eindrapport aanvullend lesmateriaal Voortgezet Onderwijs en Primair Onderwijs Europa, Utrecht: januari 2018.

Raad van State, Europa heeft geen grote debatten nodig, maar resultaten, Jaarverslag 2017, Den Haag: 12 april 2018.

Sociaal en Cultureel Planbureau, Burgerperspectieven 2016/3, Den Haag; 2016.

Verhelst, T. 'Processes and patterns of urban Europeanisation. Evidence from the EUROCITIES network', International Journal of Urban Planning, 2017/1, p. 75-97.

Wetenschappelijke Raad voor het Regeringsbeleid (WRR), Europa in Nederland, Den Haag: 2007. 